\title{
Tzanck smear in diagnosing genital herpes
}

\author{
E FOLKERS,* A P ORANJE, $†$ J N DUIVENVOORDEN, $\ddagger$ J P W VAN DER VEEN, $\S$ \\ J U RIJLAARSDAM,§ J A EMSBROEK\|
}

From the Departments of *Dermatology, and $\ddagger$ Pathology, Hospital “de Heel”, Zaandam; the $\dagger$ Department of
Dermatology and Venereology, Erasmus University and Sophia Children's Hospital/Academic Hospital,
Rotterdam; the $\S$ Department of Dermatology, Free University, Amsterdam; and the $\|$ Clinic for Sexually
Transmitted Diseases of the Municipal Health Service (GG\&GD), Amsterdam, The Netherlands

SUMMARY In 126 patients with anogenital lesions, in which herpes simplex virus (HSV) infection was suspected or included in the differential diagnosis, the results of cytodiagnosis of herpetic infection (Tzanck smear) were compared with virus culture. Cervical lesions were excluded from this study.

HSV infection was proved by culture in 78 patients and was absent or non-active in 41 patients. Excluded from this study were seven patients who did not yield the virus on culture but had positive Tzanck smear results from three investigators. The characteristic cytopathic effect of herpetic infection was found in 78 patients who yielded HSV on culture. Tzanck smear sensitivity for skin lesions was $79 \%$ and for mucous membrane lesions was $81 \%$ in men and $52 \%$ in women. Tzanck smear specificity for the 41 patients without herpetic infection proved by virus culture was $93 \%$. Differences in sensitivity and specificity between the results found by three investigators (double blind screening) were not significant. The Tzanck smear is reliable, inexpensive, and easy and quick to perform; it is suitable for office diagnosis because it does not require a specialised laboratory.

Herpetic infections of the skin and adjacent mucous membranes can be diagnosed by clinical features in most cases. In patients with an inconclusive clinical diagnosis, in whom herpetic infection is suspected, confirmation by laboratory tests will be necessary. ${ }^{1}$ Virus culture remains the standard method, but direct and quick confirmation of these herpetic infections can be obtained by the Tzanck smear.

In previous studies, we reported our experience with a cytopathological test based on the Tzanck smear in diagnosing herpetic and non-herpetic vesicular and bullous skin disorders in paediatric practice and in varicella-zoster virus infections (Folkers $\mathrm{E}$ et al, unpublished observation).' We obtained a sensitivity of the Tzanck smear in herpetic infection of more than $80 \%$ and a specificity of at least $90 \%$. We confirmed previous reports, that the Tzanck smear is a useful tool in diagnosing cutaneous herpetic infections. ${ }^{34}$

Results of this study were presented at the Spring Meeting of the Medical Society for the Study of Venereal Diseases (MSSVD) and the Dutch Society for the Study of Sexually Transmitted Diseases (NVSSOA) held in Antwerp, Belgium, in May 1987.

Address for reprints: Dr E Folkers, Department of Dermatovenereology, Hospital "de Heel”, PO Box 210, NL-1500 EE Zaandam, The Netherlands

Accepted for publication 14 December 1987
In this study we describe the application of the Tzanck smear for anogenital lesions suspected of being caused by herpes simplex virus (HSV) infection, and we compare the results with those of virus culture.

\section{Patients, materials, and methods}

\section{PATIENTS}

From May 20 to December 311986 at one of the outpatient clinics for sexually transmitted diseases (STDs) of the Municipal Health Service in Amsterdam we collected Tzanck smears from 126 patients with anogenital lesions, in which HSV infection was suspected or included in the differential diagnosis. Lesions of the skin $(n=46)$ and mucous membranes $(n=80)$ were classified as being vesicular, pustular, or ulcerous. Cervical specimens were excluded as cervical cytology is hard for inexperienced observers to judge.

\section{TZANCK SMEAR}

A Tzanck smear was routinely taken first, followed by a swab for virus culture. Scrapings from the edge and base of each vesicle, pustule, or erosion were smeared on to a glass slide, air dried, stained with Diff-Quik (Merz-Dade AG, 3186 Düdingen, Switzerland) according to the manufacturer's instructions, after which the smear was examined by light microscopy 


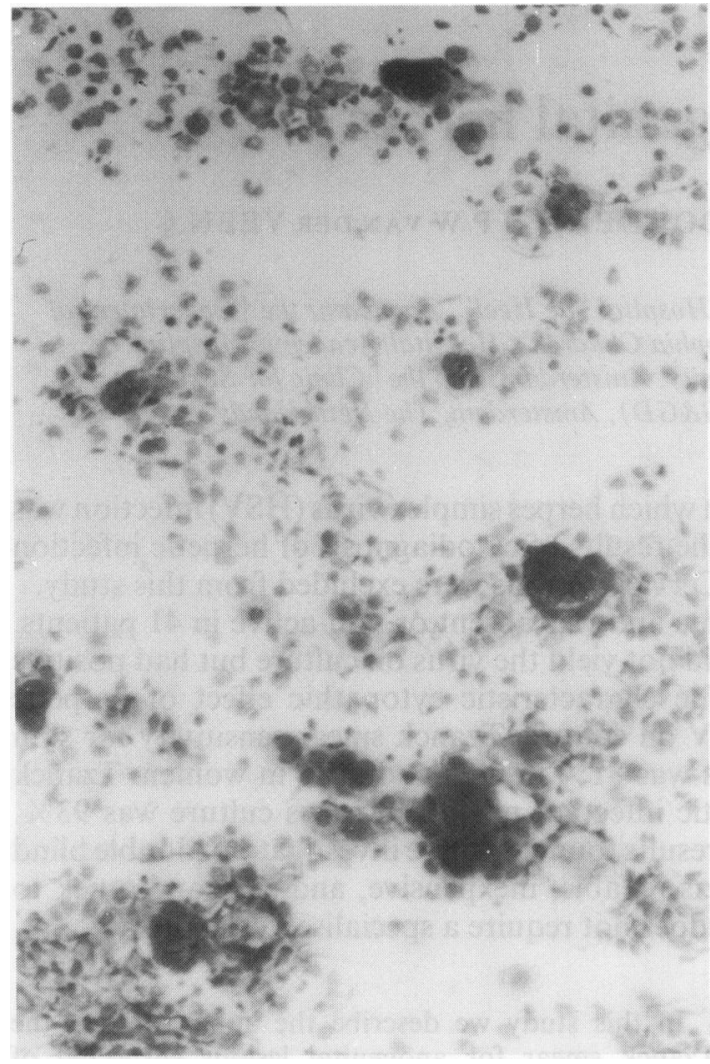

Fig 1 Tzanck smear of genital mucosal ulcer showing multiple different multinucleated epithelial giant cells, abundant erythrocytes, and sporadic leukocytes (Diff-Quik stain).

(ocular $10 \times$, objectives $10 \times, 25 \times$, and $40 \times$ magnification).

All Tzanck preparations were examined first by one investigator (EF, dermatovenereologist) and then double blind by two others (APO, dermatovenereologist, and JND, cytotechnologist).

\section{CRITERIA FOR MICROSCOPIC DIAGNOSIS OF HER PETIC INFECTION}

Epithelial cells showing characteristic and typical herpetic changes were classified as positive. These changes include enlargement, multinucleation and crowding of the nuclei with nuclear "moulding", different stages of peripheral margination of the nuclear chromatin, and alteration of the ground substance, which can be more coarse or have an opaque ("ground glass") appearance. As well as the nuclear changes described above, mononucleate, nongiant cell virocytes can also be seen (figs 1-4). Sometimes intranuclear inclusions surrounded by a prominent halo are recognisable. ${ }^{67}$

\section{VIRUS CULTURE}

After a sample had been taken for Tzanck preparation, the base and edge of each lesion were swabbed vigorously, and the specimen was transferred immediately into a viral transport medium. Virus culture and HSV subtyping were carried out according to standard virological procedures for HSV diagnosis.

\section{DEFINITIONS}

Definitions of sensitivity, specificity, and the predictive value of a positive or negative result of Tzanck smear, were as described previously. ${ }^{\prime}$

Sensitivity $=\frac{\text { No culture and Tzanck test positive }}{\text { No culture positive people tested }} \times 100$

Specificity $=\frac{\text { No culture and Tzanck test negative }}{\text { No culture negative people tested }} \times 100$

Predictive value of a positive test result $(\mathrm{PV}+)$ :

$$
\mathbf{P V}+=\frac{\text { No culture and Tzanck test positive }}{\text { No Tzanck test positive }}
$$

Predictive value of a negative test $(\mathrm{PV}-)$ :

$$
\text { PV }-=\frac{\text { No culture and Tzanck test negative }}{\text { No Tzanck test negative }}
$$

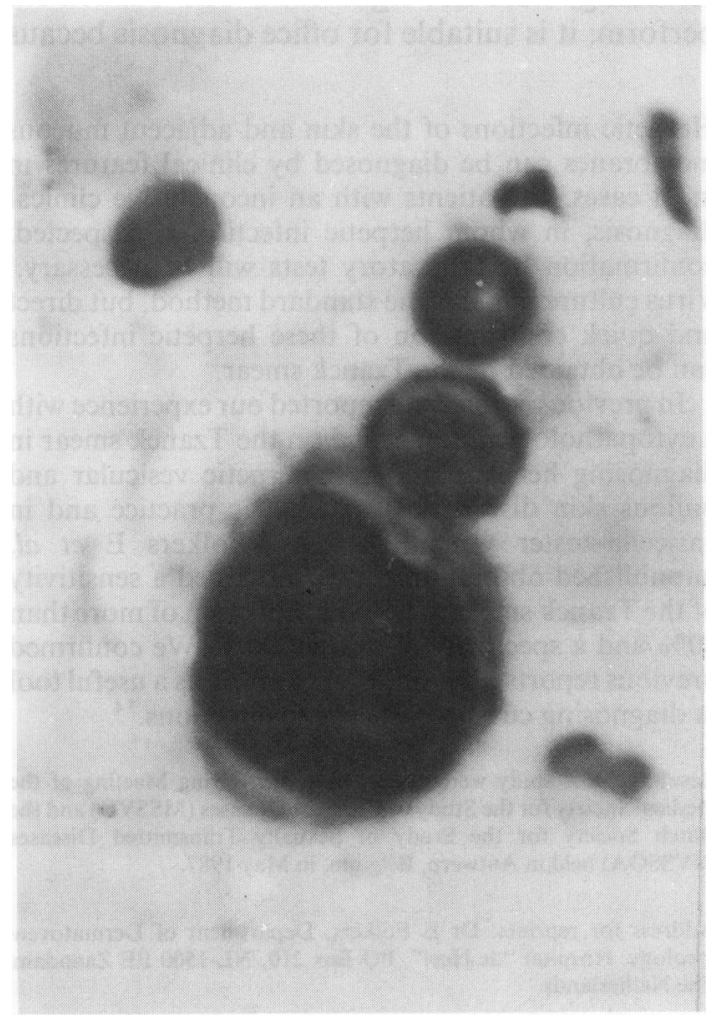

Fig 2 Mononucleated epithelial giant cell (Diff-Quik stain). 


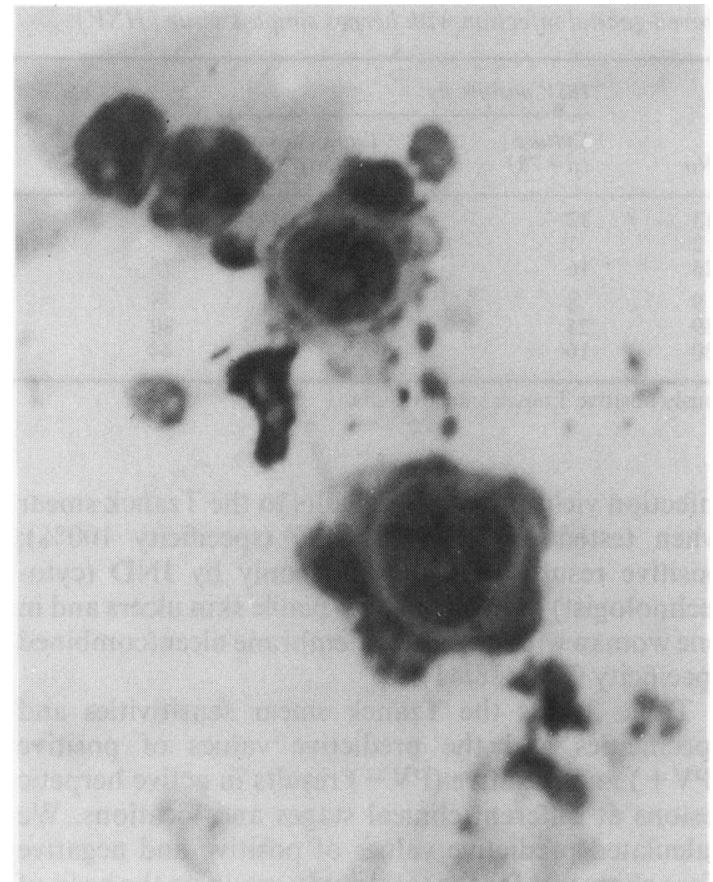

Fig 3 Epithelial giant cell with multinucleation (Diff-Quik stain).

\section{STATISTICAL ANAL YSIS}

McNemar's test was used to compare the percentages of positive and negative results obtained by different investigators (EF, APO, and JND) of Tzanck smears from the same patients. ${ }^{8}$

\section{Results}

\section{CLINICAL FEATURES}

Of 126 patients with clinically overt genital herpetic infection or genital herpes in the differential diagnosis, 78 yielded the virus on culture. HSV could not be cultured from 48 specimens: in two men syphilis was diagnosed, in seven patients the diagnosis of herpetic infection was maintained because of positive Tzanck smear results by all investigators, and in 39 patients lesions were finally classified as "ulcers of unknown cause".

The 46 skin lesions were found on the penis (30), scrotum (1), vulva (1), perineum (2), anorectal region (5), buttocks (2), pubic region (3), and groins (2). In men, Tzanck smears were taken from mucous membrane lesions on the glans penis, coronal sulcus, or sub-preputial sac (35), and from the anorectal mucous membrane (6). In women, Tzanck smears were taken from mucous membrane lesions in the vestibule or vagina (39). More lesions were ulcerous (99) than vesicular (25) or pustular (2). The average duration of the vesicular lesions of the skin and mucous membranes of men and women at the time of sampling was about two days, and of ulcerous skin lesions was about five days; the average duration of ulcerous mucous membrane lesions at the time of sampling was about four days in men and six days in women.

No laboratory investigations were undertaken to classify the basic type of the herpetic episodes in the population investigated. Based on each patient's history, 14 were experiencing an initial episode and 28 a recurrence of genital herpes. Insufficient data were available to classify the basic type of herpetic episode experienced by the remaining 84 patients (including 41 finally regarded as having no or non-active herpetic infection).

\section{VIRUS CULTURE}

HSV 2 serotype was found in 76 and HSV 1 in two isolates. Table 1 shows that HSV was isolated from 12 out of 13 vesicular, 1 out of 2 pustular, and 16 out of 26 ulcerous skin lesions; 8 out of 9 vesicular mucous membrane lesions; and 25 out of 39 ulcerous mucous membrane lesions in men and 16 out of 30 ulcerous mucous membrane lesions in women.

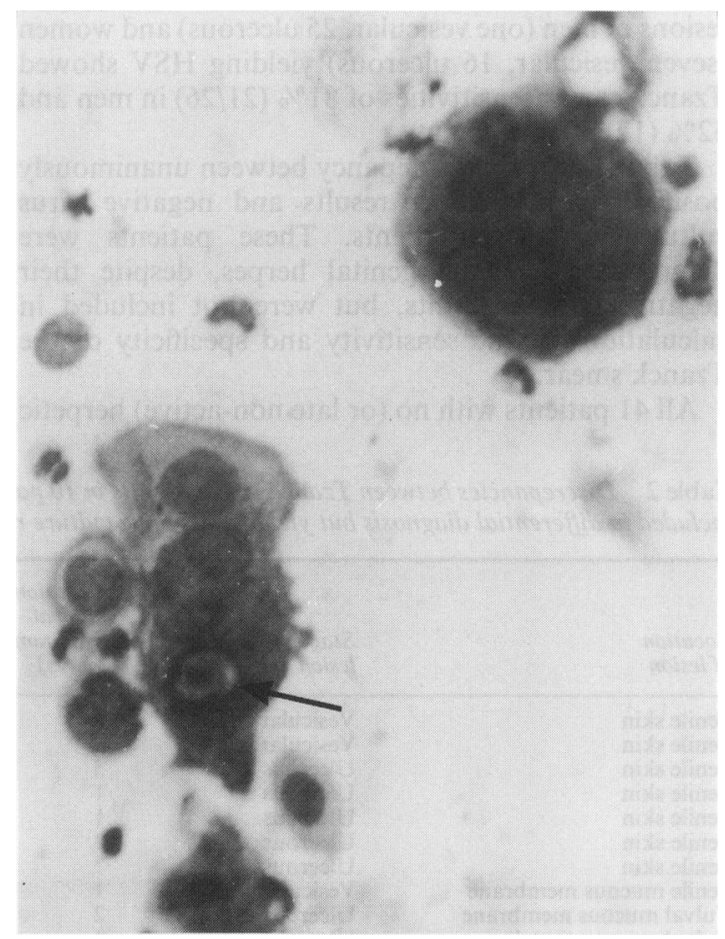

Fig 4 Multinucleated epithelial giant cells, one with an inclusion body (arrowed) (Diff-Quik stain). 
Table 1 Tzanck smear sensitivity in 119* patients with culture proved genital infection with herpes simplex virus (HSV)

\begin{tabular}{|c|c|c|c|c|c|c|}
\hline \multirow[b]{2}{*}{$\begin{array}{l}\text { Location } \\
\text { of lesions }\end{array}$} & \multirow[b]{2}{*}{$\begin{array}{l}\text { Sex of } \\
\text { patients }\end{array}$} & \multirow[b]{2}{*}{$\begin{array}{l}\text { Stage of } \\
\text { lesions }\end{array}$} & \multirow[b]{2}{*}{ No } & \multicolumn{2}{|c|}{ HSV positive by: } & \multirow[b]{2}{*}{$\begin{array}{l}\text { Sensitivity } \\
\%\end{array}$} \\
\hline & & & & $\begin{array}{l}\text { Culture } \\
(n=78)\end{array}$ & $\begin{array}{l}\text { Tzanck smear } \\
(n=56)^{* *}\end{array}$ & \\
\hline Skin & $\begin{array}{l}\text { Men and } \\
\text { women }\end{array}$ & $\left\{\begin{array}{l}\text { Vesicular } \\
\text { Pustular } \\
\text { Ulcerous }\end{array}\right.$ & $\begin{array}{r}13 \\
2 \\
26\end{array}$ & $\begin{array}{r}12 \\
1 \\
16\end{array}$ & $\left.\begin{array}{r}10 \\
12\end{array}\right\}$ & $\begin{array}{l}85 \\
75\end{array}$ \\
\hline Mucous membrane & $\begin{array}{l}\text { Men and women } \\
\text { Men } \\
\text { Women }\end{array}$ & $\begin{array}{l}\text { Vesicular } \\
\text { Ulcerous } \\
\text { Ulcerous }\end{array}$ & $\begin{array}{r}9 \\
39 \\
30\end{array}$ & $\begin{array}{r}8 \\
25 \\
16\end{array}$ & $\begin{array}{r}6 \\
20 \\
7\end{array}$ & $\begin{array}{l}75 \\
80 \\
44\end{array}$ \\
\hline
\end{tabular}

*Excluding seven patients not yielding virus on culture, but with unanimously positive Tzanck smear results.

**Results obtained by APO.

TZANCK SMEAR

The most important factors in obtaining a positive Tzanck smear were the stage of lesion development at the time of sampling and whether it was located on skin or mucous membrane. These data are also listed in table 1.

Tzanck smear sensitivity was measured against positive HSV culture results, and was $72 \%$ with APO, $77 \%$ with EF, and $81 \%$ with JND (data not given). Using McNemar's test these differences were not significant $(p>0 \cdot 1)$. Tzanck smear sensitivity for all skin lesions (in men and women together) that yielded HSV on culture was $79 \%(23 / 29)$. Mucous membrane lesions of men (one vesicular, 25 ulcerous) and women (seven vesicular, 16 ulcerous) yielding HSV showed Tzanck smear sensitivities of $81 \%(21 / 26)$ in men and $52 \%(12 / 23)$ in women.

Table 2 shows a discrepancy between unanimously positive Tzanck smear results and negative virus culture in seven patients. These patients were diagnosed as having genital herpes, despite their negative culture results, but were not included in calculations of the sensitivity and specificity of the Tzanck smear.

All 41 patients with no (or late non-active) herpetic infection yielded negative results to the Tzanck smear when tested by EF and APO (specificity 100\%); positive results were obtained only by JND (cytotechnologist) in two men with penile skin ulcers and in one woman with a mucous membrane ulcer (combined specificity $93 \%(38 / 41)$ ).

Table 3 lists the Tzanck smear sensitivities and specificities and the predictive values of positive $(\mathrm{PV}+)$ and negative $(\mathrm{PV}-)$ results in active herpetic lesions at different clinical stages and locations. We calculated predictive values of positive and negative Tzanck smears for the total study group on the basis of $72 \%$ sensitivity and $93 \%$ specificity. The prevalence of active genital herpes (proved by virus culture) in the study population was about $65 \%(78 / 119)$. The predictive value of a positive Tzanck smear $(\mathrm{PV}+)$ was 0.95 and of a negative Tzanck smear $(\mathrm{PV}-)$ was 0.64 .

\section{Discussion}

In treating genital herpes, confirmation of the clinical diagnosis of HSV infection is desirable. Acyclovir, the preferred drug for antiviral treatment, is more effective the earlier it is given. ${ }^{9}$ As swift diagnosis can therefore

Table 2 Discrepancies between Tzanck smear results in 10 patients with genital lesions in which genital herpes was suspected or included in differential diagnosis but yielding negative culture results

\begin{tabular}{|c|c|c|c|c|c|}
\hline \multirow{2}{*}{$\begin{array}{l}\text { Location } \\
\text { of lesion }\end{array}$} & \multirow{2}{*}{$\begin{array}{l}\text { Stage of } \\
\text { lesion }\end{array}$} & \multirow{2}{*}{$\begin{array}{l}\text { Duration of } \\
\text { clinical } \\
\text { symptoms } \\
\text { (days) }\end{array}$} & \multicolumn{3}{|c|}{ Tzanck smear by: } \\
\hline & & & $E F$ & $A P O$ & $J N D$ \\
\hline $\begin{array}{l}\text { Penile skin } \\
\text { Penile skin } \\
\text { Penile skin } \\
\text { Penile skin } \\
\text { Penile skin } \\
\text { Penile skin } \\
\text { Penile skin } \\
\text { Penile mucous membrane } \\
\text { Vulval mucous membrane } \\
\text { Vulval mucous membrane }\end{array}$ & $\begin{array}{l}\text { Vesicular } \\
\text { Vesicular } \\
\text { Ulcerous } \\
\text { Ulcerous } \\
\text { Ulcerous } \\
\text { Ulcerous } \\
\text { Ulcerous } \\
\text { Vesicular } \\
\text { Ulcerous } \\
\text { Ulcerous }\end{array}$ & $\begin{array}{l}2 \\
? \\
5 \\
1 \\
1 \\
? \\
? \\
1 \\
2 \\
?\end{array}$ & $\begin{array}{l}+ \\
+ \\
+ \\
+ \\
+ \\
- \\
+ \\
+ \\
+\end{array}$ & $\begin{array}{l}+ \\
+ \\
+ \\
+ \\
+ \\
- \\
+ \\
+ \\
+\end{array}$ & $\begin{array}{l}+ \\
+ \\
+ \\
+ \\
+ \\
+ \\
+ \\
+ \\
+ \\
+\end{array}$ \\
\hline
\end{tabular}


Table 3 Sensitivity, specificity, and predictive values of positive $(P V+)$ and negative $(P V-)$ results of Tzanck smears obtained from lesions at different stages and locations in patients with herpetic infection proved by virus culture

\begin{tabular}{|c|c|c|c|c|c|c|c|}
\hline Location & $\begin{array}{l}\text { Stage of } \\
\text { lesion }\end{array}$ & $\begin{array}{l}\text { Sex of } \\
\text { patients }\end{array}$ & $\begin{array}{l}\text { Sensitivity } \\
\%\end{array}$ & $\begin{array}{l}\text { Specificity } \\
\%\end{array}$ & $\begin{array}{l}\text { Prevalence } \\
\%\end{array}$ & $P V+$ & $P V-$ \\
\hline \multirow{3}{*}{$\begin{array}{l}\text { Skin } \\
\text { Mucous membrane } \\
\text { Skin } \\
\text { Mucous membrane } \\
\text { Mucous membrane } \\
\text { Total }\end{array}$} & Vesicular or pustular & Men and women & 81 & 100 & 88 & 1 & 0.42 \\
\hline & $\begin{array}{l}\text { Ulcerous } \\
\text { Ulcerous } \\
\text { Ulcerous }\end{array}$ & $\begin{array}{l}\text { Men and women } \\
\text { Men } \\
\text { Women }\end{array}$ & $\begin{array}{l}75 \\
80 \\
44\end{array}$ & $\begin{array}{l}92 \dagger \\
92 \dagger \\
92 \dagger\end{array}$ & $\begin{array}{l}62 \\
64 \\
53\end{array}$ & $\begin{array}{l}0.94 \\
0.95 \\
0.86\end{array}$ & $\begin{array}{l}0.69 \\
0.72 \\
0.59\end{array}$ \\
\hline & & & 72 & 93 & 65 & 0.95 & 0.64 \\
\hline
\end{tabular}

*Prevalence of culture proved herpetic infection in lesions of patients suspected of having genital herpes or in whose differential diagnosis it was included.

†Summarised specificity obtained in all ulcerous lesions (no clear differences obtained between women and men).

lead to more effective treatment, the advantage of a rapid diagnostic test is obvious.

Several rapid direct diagnostic tests using monoclonal antibody immunofluorescence or immunoperoxidase techniques have been developed recently, but these do not yet show acceptable sensitivity and specificity compared with virus culture. ${ }^{10}$ Culture is still the standard verification method for HSV infections, and it can confirm the clinical diagnosis within 24 hours. $^{10} 11$ It does not, however, reach $100 \%$ sensitivity even in clinically typical cases. ${ }^{3} \mathrm{HSV}$ culture commonly gives positive results in the vesicular and pustular stages of the infection, but its sensitivity decreases considerably when lesions are old and crusted or in the ulcerous stage. ${ }^{312}$

Direct and rapid confirmation of herpetic infection, though not specific for HSV 1, HSV 2, or varicellazoster virus, is possible with the Tzanck smear, using rapid staining techniques. ${ }^{513}$ Our previous study, which was conducted in a paediatric clinic and focused on herpetic and non-herpetic vesicular and bullous skin disorders, indicated the high sensitivity $(80 \%)$ and specificity $(90 \%)$ of the Tzanck smear. The Tzanck smear as a diagnostic tool can reliably support a clinical diagnosis of herpetic skin infections. ${ }^{1-4}$

Clinicians can easily obtain experience in using the Tzanck smear effectively in office practice with the help of supplemental screening by a cytopathologist or cytotechnologist. We do not consider routine Tzanck smear examination to be suitable for office diagnosis of cervical lesions, because examining cervical smears is complex, takes time, and demands cytopathological experience. Cervical lesions were therefore excluded from this study. Nevertheless a positive Tzanck smear of cervical specimens can support the diagnosis of HSV infection.

The two most important factors in obtaining positive Tzanck smear results were the stage of the infection at the time of sampling and the location of the lesion. Moseley et al reported a Tzanck smear sensitivity of $38 \%$ in genital herpes. ${ }^{14}$ Our study, however, indicated a higher sensitivity of the Tzanck smear. The Tzanck smear sensitivity in skin lesions of our patients yielding virus on culture was $79 \%$. In vesicular lesions of skin and mucous membranes, the Tzanck smear reached a sensitivity of $81 \%$ in patients with culture proved genital herpes infection. Tzanck smear sensitivity was $80 \%$ in men and $44 \%$ in women with HSV positive ulcerous mucous membrane lesions. In the total group of patients with culture proved genital herpes the summarised Tzanck smear sensitivity compared with virus culture was $72 \%$.

A discrepancy between a unanimously positive Tzanck smear result and negative culture results was found in seven patients. These can probably be considered as culture failures. These patients were finally assigned a clinical diagnosis of genital herpes, but they were not included in the calculations of this study. As already mentioned, the sensitivity of HSV culture is not $100 \%$, but is presumably more than $90 \%$.

The results showed reduced Tzanck smear sensitivities with differing sites of infection and stages of lesions. The average duration of ulcerous skin lesions was about five days and of ulcerous mucous membrane lesions about four days in men and six days in women.

Viral shedding decreases with the duration of herpetic lesions. A decrease in viral shedding from herpetic lesions of longer duration may correlate with the lower sensitivity of the Tzanck smear. The speed with which cell cultures develop a cytopathological effect (CPE) can be used to estimate roughly the amount of herpes virus antigen present in the lesions investigated. We found no appreciable difference, however, in average time to developing CPE in herpetic mucous membrane lesions between men (7.7 days) and women (7.4 days).

Necrotic syncytial giant cells can be found in herpetic lesions that are more than 72 hours old. The characteristic cytomorphological features of herpetic infection are obscured by the rapid loss of nuclear details in cells infected for longer. ${ }^{6}$ The longer average duration of ulcerous mucous membrane lesions in 
women in this study compared with the other herpetic lesions investigated might be a cytomorphological explanation for the lower Tzanck smear sensitivity.

In vesicular lesions, a Tzanck smear specificity of $100 \%$ was obtained by all investigators. This study showed a summarised specificity of at least $93 \%$ for the Tzanck smear in genital herpes with lesions of skin and adjacent mucous membranes. By using McNemar's test, statistical analysis showed no significant differences between the Tzanck smear sensitivity and specificity obtained by EF, APO, and JND. With the aid of sensitivity, specificity, and prevalence figures, the predictive values for positive $(\mathrm{PV}+)$ and negative (PV -$)$ results were calculated. The best PV + was attained in vesicular lesions, the best PV - in mucous membrane ulcers of men.

Positive and negative predictive values depend on the prevalence of the disease in the population investigated. With lower prevalence figures the PV+ decreases, but the PV - increases. For example, a prevalence of $50 \%$ would give a PV + of 0.91 and a $\mathrm{PV}$ - of 0.77 , whereas a prevalence of $10 \%$ would give a PV + of 0.5 and a PV - of 0.97 . In the population attending this STD clinic the prevalence of herpetic infections proved by virus culture of ulcerous genital lesions is about $50 \%$.

The usefulness of a test with a given sensitivity and specificity depends on the purpose it has to be used for. For screening in high risk populations, such as prostitutes, tests with a high sensitivity giving minimum false negative test results are desirable, in which case a high PV - will be obtained. Cytodiagnosis of herpetic infection cannot respond to criteria of a routine screening test excluding herpetic infection; the Tzanck test is therefore not suitable for antenatal screening for HSV infection. On the other hand positive Tzanck smear results are very reliable in confirming the clinical diagnosis of herpetic infection.

In cytodiagnosis PV + and PV - values depend on the skill and experience of the observer. Application of the Tzanck smear routinely in herpetic infections has the advantage of helping observers to gain and maintain experience with cytodiagnosis, so that they can rely on observation and interpretation of the test in cases with inconclusive clinical diagnosis. A positive Tzanck smear result in patients with equivocal clinical features may even obviate the need for virus culture, thus saving cost.

Immunofluorescence cytology using monoclonal antibodies potentially increases the specificity and sensitivity of cytological preparations, but this method is time consuming and therefore not particularly suitable for office diagnosis. ${ }^{49}$ Further investigation of this technique is required.

This study, conducted in an STD clinic, shows Tzanck smear results of comparable sensitivity and specificity to those of our previous investigation ${ }^{1}$ (with the exception of the results of Tzanck smear sensitivity obtained in women with ulcerous mucous membrane lesions). Our results show highly reliable positive Tzanck smear results in venereological practice. Moreover this test is inexpensive, quick, and easy to perform, which makes it suitable for office diagnosis.

In dermatological and venereological practice, a positive Tzanck smear result can lead to rapid confirmation of the diagnosis of herpetic infection, prompt treatment with acyclovir, if necessary, and greater assurance of the drug's therapeutic effect. Confirmation of clinically diagnosed herpetic infection is possible with the Tzanck smear, even when virus culture fails.

We thank H J A Schouten, Department of Medical Informatics and Statistics, University of Limburg, Maastricht, for statistical advice, and the staff of this clinic for their part in this investigation, particularly Sylvia Bos, Adrienne Flipse, and Joyce Noordhoek Hegt-de Graaf for technical help, and Wies van Bolderik and Yvonne Creusen for supplying data on patients.

\section{References}

1 Oranje AP, Folkers E, Choufoer-Habova J, Duivenvoorden JN. Diagnostic value of Tzanck smear in herpetic and non-herpetic vesicular and bullous skin disorders in pediatric practice. Acta Derm Venereol (Stockh) 1986;66:127-33.

3 Solomon AR, Rasmussen JE, Varani J, Pierson CL. The Tzanck smear in the diagnosis of cutaneous herpes simplex. JAMA 1984;251:633-5.

4 Solomon AR, Rasmussen JE, Weiss JS. A comparison of the Tzanck smear and viral isolation in varicella and herpes zoster. Arch Dermatol 1986;122:282-5.

5 O'Keefe EJ, Burke WA, Steinbaugh JR. Diff-Quik stain for Tzanck smears. J Am Acad Dermatol 1985;13:148-9.

6 Barr RJ. Cutaneous cytology. J Aim Acad Dermatol 1984;10: 163-80.

7 Solomon AR. The Tzanck smear viable and valuable in the diagnosis of herpes simplex, zoster, and varicella. Int J Dermatol 1986;25:169-70.

8 Siegel S. Nonparametric statistics of the behavioral sciences. New York: McGraw Hill, 1956.

9 Longson M. Herpes simplex. In: Zuckerman AJ, Banatvala JE, Patison JR, eds. Principles and practice of clinical virology. Chichester: John Wiley \& Sons, 1987:3-49.

10 Salmon VC, Turner RB, Speranza MJ, Overall JC. Rapid detection of herpes simplex virus in clinical specimens by centrifugation and immunoperoxidase staining. $J$ Clin Microbiol 1986;23:683-6.

11 Gleaves CA, Wilson DJ, Wold AD, Smith TF. Detection and serotyping of herpes simplex virus in MRC-5 cells by use of centrifugation and monoclonal antibodies $16 \mathrm{~h}$ postinoculation. J Clin Microbiol 1985;21:29-32.

12 Veien NK, Vestergaard BF. Rapid diagnostic tests for cutaneous eruptions of herpes simplex. Acta Derm Venereol (Stockh) 1978;58:83-5.

13 Folkers E, Oranje AP. Een snelle diagnostische test (Tzanck-test) ter uitsluiting van herpesvirusinfecties bij blaasjes, blaren en pustels. ("A rapid diagnostic test (Tzanck test) to exclude herpesvirus infections in vesicles, blisters and pustules") Ned Tijdschr Geneeskd 1985;129:241-3.

14 Moseley RC, Corey L, Benjamin D, Winter C, Remington ML. Comparison of viral isolation, direct immunofluorescence, and indirect immunoperoxidase techniques for detection of genital herpes simplex virus infection. J Clin Microbiol 1981;13:913-8. 